\title{
Aerobic Degradation of Trichloroethylene by a New Type II Methane-Utilizing Bacterium, Strain M
}

\author{
Hiroo UchiYama, ${ }^{\dagger}$ Toshiaki NaKaJima, ${ }^{*}$ Osami YagI \\ and Takeshi TABUCHI \\ Water and Soil Environment Division, The National Institute for \\ Environmental Studies, Tsukuba 305, Japan \\ * Institute of Applied Biochemistry, University of Tsukuba, \\ Tsukuba 305, Japan \\ Received April 28, 1989
}

\begin{abstract}
An aerobic, methane-utilizing bacterium (methanotroph, strain $M$ ) was isolated that degraded trichloroethylene (TCE) in a pure culture at a high concentration, $10 \mathrm{ppm}$. Strain $\mathrm{M}$ used methane or methanol as the sole carbon and energy source for growth, and no growth occurred on nutrient broth or glucose. The strain exhibited intracytoplasmic membranes along the cell periphery, and the taxonomical properties indicated that strain $M$ was a new methanotroph belonging to obligate type II. In addition, strain $M$ was able to degrade not only TCE, but also halogenated alkenes (i.e., 1,1dichloroethylene, both cis- and trans-1,2-dichloroethylene, and 1,2-dibromoethylene) and alkanes (i.e., 1,1,2-trichloroethane, 1,2-dichloroethane and chloroform), but not tetrachloroethylene, 1,1,1-trichloroethane, carbon tetrachloride or aromatic compounds.
\end{abstract}

Volatile, chlorinated aliphatic compounds such as tetrachloroethylene, trichloroethylene (TCE), chloroform and 1,1,1-trichloroethane have been detected in groundwater, ${ }^{1,2)}$ with TCE being predominant. TCE, which is considered to be a carcinogen in rats, ${ }^{3)}$ is resistant to biodegradation in the environment. ${ }^{4)}$ However, consortia of anaerobic microorganisms have been found to degrade TCE. ${ }^{5,6)}$ Unfortunately, some anaerobic bacteria degrade TCE to yield vinyl chloride, which is known to be strongly carcinogenic for mantmals. ${ }^{7)}$ Recently, under aerobic conditions, mixtures of bacteria have been reported to degrade TCE with the addition of methane..$^{5,8}$ These aeróbic degradations were considered to be associated with the metabolic activities of the methanotrophs. However, the aerobically degradable TCE concentrations reported were very low (less than $1 \mathrm{ppm}$ ). More recently, four pure bacterial cultures, strain $46-1,{ }^{9)}$ strain G4, ${ }^{10)}$ Pseudomonas putida $\mathrm{F}^{11}{ }^{11}$ and Pseudomonas putida $\mathrm{B} 5,{ }^{12)}$ have been reported to degrade TCE. Strain 46-1, a methanotroph belonging to type I, was shown to degrade 400 ppb TCE. The latter three strains were not methanotrophs and required aromatic compounds, such as phenol, to degrade TCE. In the previous study, ${ }^{13)}$ we also isolated a new methane-utilizing mixed culture (MU-81) including a type II methanotroph, which was capable of degrading $10 \mathrm{ppm}$ TCE. It thus seemed important to determine whether or not such an ability to degrade TCE at a high concentration was due to the special characteristics of strain $M$. In this study, we isolated strain $\mathrm{M}$ from the mixed culture and examined its ability to degrade TCE at high concentrations as well as other compounds. Furthermore, the characteristics of strain $M$ and its taxonomic position were examined.

\section{Materials and Methods}

Chemicals. All the gaseous compounds, volatile chlorinated organic compounds and fatty acids were purchased

\footnotetext{
+ Corresponding author.
} 
from Gaskuro-kogyo Co., Tokyo.

Single colony isolation. The mixed culture, MU-81, was streaked onto mineral salt agarose plates. ${ }^{13)}$ The agarose plates were incubated in a desiccator under an atmosphere of methane and air $(1: 1, \mathrm{v} / \mathrm{v})$ at $30^{\circ} \mathrm{C}$. An isolated colony was picked up and restreaked. This procedure was repeated at least five times.

Identification methods. Cells used for the determination of characteristics were grown on the mineral salt medium under a methane-air atmosphere, as previously described. ${ }^{13)}$ Flagella staining was carried out as described by Mayfield and Inniss. ${ }^{14)}$ Motility was examined by the hanging drop method. The membrane arrangement was observed with a model JEOL 2000FX transmission electron microscope at $80 \mathrm{kV}$ after negative staining with $0.5 \%$ uranyl acetate followed by lead citrate. ${ }^{15}$ Cell morphology was observed with a model JEOL 840 scanning electron microscope at $15 \mathrm{kV}$ after fixation with $1 \%$ glutaraldehyde. ${ }^{16)}$ In the assimilation test for carbon compounds, for the gaseous compounds, air $(20 \mathrm{ml})$ was withdrawn from each bottle with a syringe and the compound to be tested $(20 \mathrm{ml})$ was injected to replace the air. For liquid compounds, $0.3 \mathrm{ml}$ of the compound to be tested was introduced into the bottle to a final concentration of $1 \%$ $(\mathrm{v} / \mathrm{v})$, but in the case of glucose, to a final concentration of $1 \%(\mathrm{w} / \mathrm{v})$. The DNA base composition, cellular fatty acid composition and quinone system were analysed by the method described by Komagata et al. ${ }^{17)}$

Degradation experiments. TCE degradation experiments were performed in a similar manner to those previously described. ${ }^{13)}$ The degradation of TCE and other volatile halogenated compounds was monitored by measuring their concentrations by the headspace method, as previously described. ${ }^{13)}$ Aromatic compounds were assayed according to the method of Higgins et al. ${ }^{18)}$

\section{Results}

\section{Single colony isolation}

After repeated streaking and isolation, we obtained a pure single colony, strain M. It showed a constant, homogeneous morphology over two years and the complete absence of growth on carbon compounds other than methane or methanol. Growth curves also showed a constant pattern in every cultivation experiment.

\section{Characterization of strain $M$}

Table I shows the characteristics of strain M. The cells were rods (Fig. 1A) and a thin
Table I. Description of Strain M

Morphological characteristics

Rods, $(0.6 \sim 1.0) \times(1.0 \sim 5.0) \mu \mathrm{m}$.

Non-motile. Intracytoplasmic membranes aligned to the cell periphery.

Cultural characteristics

Mineral salt medium agarose colonies*: white to buff, darkening with age.

Nutrient agar: no growth.

Methanol broth: good growth.

No additional growth factors required.

Physiological characteristics

Gram negative.

Catalase: (-). Oxidase: (-).

Grows on methane and methanol, but not on ethane, propane, $n$-butane, dimethylether, methylamine, ethanol, glucose or nutrient broth.

Grows on methane at $30^{\circ} \mathrm{C}$ and $37^{\circ} \mathrm{C}$, but not at $45^{\circ} \mathrm{C}$.

Chemical composition of cells

Predominant cellular fatty acid: $\mathrm{C}_{18: 1}(96.5 \%$ of the total fatty acids).

Hydroxy fatty acid type: $2-\mathrm{OH}$.

Quinone type: Q-8, but no menaquinone was detected.

$\mathrm{G}+\mathrm{C}$ content: $64.5 \mathrm{~mol} \%$.

* An agarose plate was incubated under an atmosphere of methane and air $(1: 1, v / v)$ at $30^{\circ} \mathrm{C}$.

section (Fig. 1B) showed a complex arrangement of intracellular membranes. These results indicated that strain $\mathrm{M}$ belongs to the type II, subgroup IIa (obligate) methanotrophs based on the description in the ninth edition of Bergey's Manual of Determinative Bacteriology, ${ }^{19)}$ and that it is distinct from other methanotrophs belonging to subgroup IIa.

\section{Time course of TCE degradation}

When incubated in a pure culture, strain $\mathrm{M}$ degraded more than $90 \%$ of added TCE in the exponential phase (Fig. 2). This TCE degradation was closely related to the cell growth, and the consumption of methane and oxygen. The disappearance curves for TCE, methane and oxygen showed similar patterns to those observed for the mixed culture, MU-81. ${ }^{13)}$

\section{Maximum concentration of TCE for degra- dation}

As shown in Fig. 3, strain $\mathrm{M}$ degraded more 


\section{A}

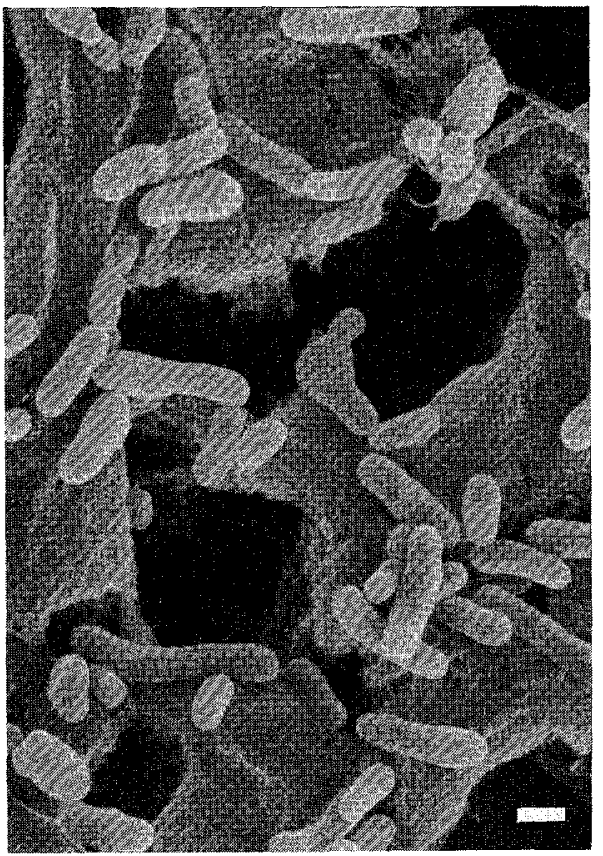

B

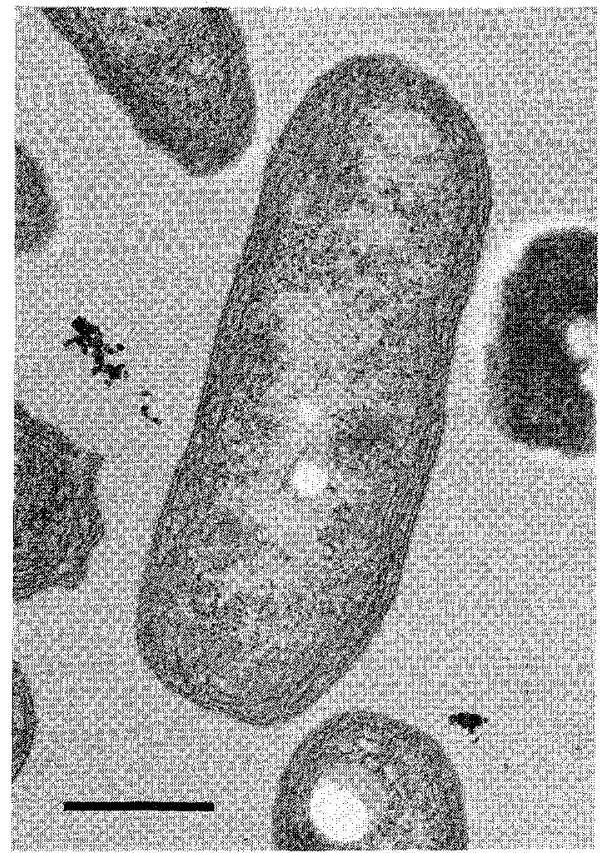

Fig. 1. Electron Micrographs of Strain M Grown on Methane.

A, scanning electron micrograph; B, thin section. The bars represent $1 \mu \mathrm{m}$, in $\mathrm{A}$, and $0.5 \mu \mathrm{m}$, in $\mathrm{B}$.

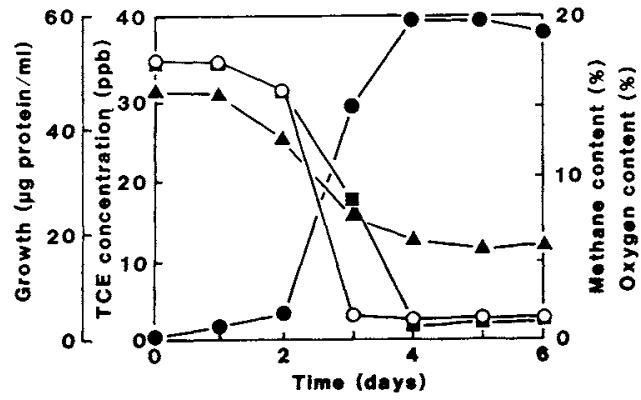

Fig. 2. Time Course of TCE Degradation by Strain M. $\bigcirc, \mathrm{TCE}$ concentration; $\boldsymbol{\Delta}$, methane content in headspace; $\mathbf{\square}$, oxygen content in headspace; $\mathbf{O}$, cell growth.

than $90 \%$ of the TCE, up to $3.5 \mathrm{ppm}$, within 9 days. At $10 \mathrm{ppm}$, the degradation ended on day 13. The addition of oxygen at the end point further stimulated TCE degradation in the mixed culture, whereas in the case of strain $M$ the degradation was not stimulated further. This may be ascribed to the accumulation of toxic compounds as well as to the total con-

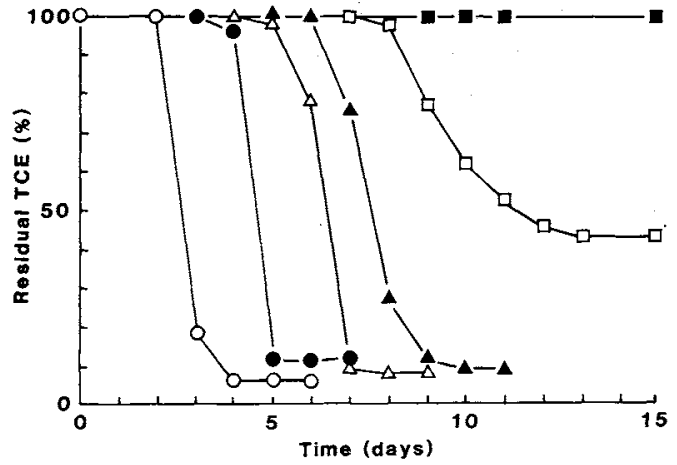

Fig. 3. TCE Degradation at Different Concentrations.

The stock culture $(50 \mu \mathrm{l})$ was inoculated into $30 \mathrm{ml}$ of medium and the experiments were performed in duplicate. The average percent decrease in TCE was compared with that in the case of the respective control which was not inoculated with strain $M$. The initial TCE concentrations were: $\bigcirc, 35 \mathrm{ppb} ; 0,0.35 \mathrm{ppm} ; \triangle, 1 \mathrm{ppm} ; \boldsymbol{\Lambda}, 3.5 \mathrm{ppm} ; \square$, $10 \mathrm{ppm} ; \mathbf{\square}, 35 \mathrm{ppm}$.

sumption of oxygen in the bottle. As $35 \mathrm{ppm}$, neither TCE degradation nor cell growth was observed during a 15 day period. 
Table II. Degradation of Different Compounds BY Strain M

\begin{tabular}{|c|c|c|c|}
\hline Compound & $\begin{array}{l}\text { Initial } \\
\text { conc. } \\
\text { (ppm) }\end{array}$ & $\begin{array}{l}\text { Culture } \\
\text { time } \\
\text { (days) }\end{array}$ & $\begin{array}{c}\text { Decrease }^{a} \\
(\%)\end{array}$ \\
\hline Tetrachloroethylene & 0.15 & 7 & 2 \\
\hline TCE & 0.35 & 7 & 96 \\
\hline 1,1-Dichloroethylene & 0.005 & 7 & 92 \\
\hline$c i s-1,2$-Dichloroethylene & 0.45 & 7 & 100 \\
\hline trans-1,2-Dichloroethylene & 0.45 & 7 & 98 \\
\hline 1,2-Dibromoethylene & 0.5 & 7 & 93 \\
\hline 1,1,1-Trichloroethane & 0.55 & 7 & 6 \\
\hline 1,1,2-Trichloroethane & 0.85 & 7 & 82 \\
\hline 1,2-Dichloroethane & 0.85 & 7 & 100 \\
\hline Carbon tetrachloride & 0.6 & 7 & 4 \\
\hline Chloroform & 0.15 & 7 & 99 \\
\hline Benzene & 10 & 10 & 6 \\
\hline Chlorobenzene & 10 & 10 & 5 \\
\hline Phenol & 10 & 10 & 9 \\
\hline Benzoic acid & 10 & 10 & 10 \\
\hline$p$-Chlorobenzoic acid & 10 & 10 & 4 \\
\hline p-Chlorobiphenyl & 10 & 10 & 2 \\
\hline
\end{tabular}

a Data represent average percent decreases compared with those in the cases of controls which were not inoculated with strain $M$. Experiments were performed in duplicate.

\section{Degradation of several alkenes, alkanes and} aromatic compounds

The action of strain $\mathbf{M}$ as to the degradation of several compounds was examined (Table II). TCE, 1,1-dichloroethylene, both cis- and trans-1,2-dichloroethylene, 1,2-dibromoethylene (mixture of cis and trans forms), 1,1,2trichloroethane, 1,2-dichloroethane and chloroform were degraded significantly within 7 days, whereas, tetrachloroethylene, 1,1,1trichloroethane, carbon tetrachloride and aromatic compounds were not degraded. As reported previously, ${ }^{13)}$ the ability to degrade halogenated alkenes and alkanes of strain $M$ was closely related to the chemical structure of the compounds, that is, incompletely halogenated compounds could be degraded, but completely halogenated could not.

\section{Discussion}

Although the aerobic degradation of TCE has been studied by several groups, $, 5,8,10 \sim 12$ ) the degradation by a pure culture was reported only by Nelson et al. ${ }^{10,12)}$ and Little et al. ${ }^{9)}$ Nelson et al. reported that one aerobic microorganism, which was not a methanotroph, degraded TCE when the organism was simultaneously exposed to phenol. Little $e t$ al. reported the TCE degradation by a type I methanotroph isolated from contaminated groundwater. We report here for the first time that a type II methanotroph is also capable of degrading TCE at high concentrations, such as $10 \mathrm{ppm}$. Methanotrophs possess a unique methane monooxygenase which enables them to utilize methane as a sole carbon and energy source. ${ }^{20)}$ The methane monooxygenase has a low substrate specificity, and is known to be able to oxidize or dechlorinate a large number of nongrowth compounds. ${ }^{21)}$ Therefore, the ability to degrade TCE seems to be a ubiquitous characteristic of methanotrophs regardless of whether they belong to type I or type II.

As shown in Fig. 3, at low concentrations of TCE (35 ppb and $0.35 \mathrm{ppm}$ ), strain $M$ degraded TCE at the same rate as the mixed culture, MU-81. ${ }^{13)}$ In contrast, at higher concentrations (above $1 \mathrm{ppm}$ ), the degradation rate was reduced. Strain $M$ required 13 days to degrade $10 \mathrm{ppm}$ TCE to a level corresponding to $40 \%$ of the initial concentration. This period was 11 days in the case of mixed culture MU-81 even though the degradation began at day 8 in both cases. ${ }^{13)}$ This phenomenon is presumably associated with the accumulation of toxic organic compounds produced from TCE by strain $M$. In the case of the mixed culture, these compounds may have been assimilated or detoxified by the heterotrophic bacteria, and strain $\mathbf{M}$ appeared to be responsible for the ability to degrade TCE, at high concentrations, as well as other halogenated compounds. The details of the roles of the heterotrophic bacteria will be presented elsewhere.

A taxonomic system for the methaneutilizing bacteria has not been established yet. $^{19)}$ Urakami and Komagata ${ }^{22)}$ classified methane-utilizing bacteria into three groups, based on their cellular fatty acid compositions. 
Whittenbury and Krieg ${ }^{19)}$ classified them into two types, types I and II, based on their intracytoplasmic membrane ultrastructures, and, furthermore, they divided type II into two subgroups, IIa (obligate) and IIb (facultative). As strain $M$ has paired membranes aggregated at the periphery of the cell and is obligate, it considered to belong to the type II, subgroup IIa methanotrophs. We consider that "Methylovibrio soehngenii" A, "Methylocystis parvus" ОВВР, "Methylosinus sporium" 5, "Methylosinus trichosporium" OB3b and "Methanomonas margaritae" should be assigned to subgroup IIa. Strain M showed characteristics different from those of these strains. Therefore, it is suggested that strain $\mathrm{M}$ belongs to a new species whose characteristics will be described elsewhere.

Acknowledgments. We wish to thank Professor K. Komagata, University of Tokyo, for the valuable and helpful discussions on the taxonomic study, and Mrs. K. Shibata of this institute for her outstanding assistance in the electron microscopy.

\section{References}

1) T. Kawasaki, Jpn. J. Water Pollut. Res., 8, 264 (1985).

2) U. S. Environmental Protection Agency, Fed. Regist., 47, 9349 (1982).

3) R. E. Miller and F. P. Guengerich, Biochemistry, 21, 1090 (1982).

4) P. F. Infante and T. A. Tsongas, Environ. Sci. Res., 25, 301 (1982).

5) M. M. Fogel, A. R. Taddeo and S. Fogel, Appl. Environ. Microbiol., 51, 720 (1986).
6) T. M. Vogel and P. McCarty, Appl. Environ. Microbiol., 49, 1080 (1985).

7) C. Maltoni and G. Lefemine, Environ. Res., 7, 387 (1974).

8) J. T. Wilson and B. H. Wilson, Appl. Environ. Microbiol., 49, 242 (1985).

9) C. D. Little, A. V. Palumbo, S. E. Herbes, M. E. Lidstrom, R. L. Tyndall and P. J. Gilmer, Appl. Environ. Microbiol., 54, 951 (1988).

10) M. J. K. Nelson, S. O. Montgomery, E. J. O'Neill and P. H. Pritchard, Appl. Environ. Microbiol., 52, 383 (1986).

11) L. P. Wackett and D. T. Gibson, Appl. Environ. Microbiol., 54, 1703 (1988).

12) M. J. K. Nelson, S. O. Montgomery and P. H. Pritchard, Appl. Environ. Microbiol., 54, 604 (1988).

13) H. Uchiyama, T. Nakajima, $O$. Yagi and $T$. Tabuchi, Agric. Biol. Chem., 53, 1019 (1989).

14) C. I. Mayfield and W. E. Inniss, Can. J. Microbiol., 23, 1311 (1977).

15) K. Takeda and K. Tanaka, Antonie van Leeuwenhoek J. Microbiol. Serol., 46, 15 (1980).

16) K. Amano and A. Umeda, I. Electron Microsc., 26, 155 (1977).

17) J. Tamaoka, D.-M. Ha and K. Komagata, Int. J. Syst. Bacteriol., 37, 52 (1987).

18) I. J. Higgins, R. C. Hammond, F. S. Sariaslani, D. Best, M. M. Davies, S. E. Tryhorn and F. Taylor, Biochem. Biophys. Res Commun., 89, 671 (1979).

19) R. Whittenbury and N. R. Krieg, in "Bergey's Manual of Systematic Bacteriology," Vol. 1, ed. by N. R. Krieg and J. G. Holt, Williams \& Wilkins Co., Baltimore, 1984, pp. 256 261.

20) H. Dalton, S. D. Prior, D. J. Leak and S. H. Stanley, in "Microbial Growth on $\mathrm{C}_{1}$ Compounds," ed. by R. L. Crawford and R. S. Hanson, American Society for Microbiology, Washington, D.C., 1984, pp. $75 \sim 82$.

21) H. Dalton and D. I. Stirling, Phil. Trans. R. Soc. London Ser. B, 297, 481 (1982).

22) T. Urakami and K. Komagata, J. Gen. Appl. Microbiol., 33, 135 (1987). 